\title{
Anti-elite politics and emotional reactions to socio-economic problems: Experimental evidence on "pocketbook anger" from France, Germany, and the United States
}

\author{
Paul Marx ${ }^{1,2}$ iD
}

${ }^{1}$ Institute for Socio-Economics, University of Duisburg-Essen, Duisburg, Germany

${ }^{2}$ Danish Center for Welfare Studies, University of Southern Denmark, Odense, Denmark

\section{Correspondence}

Paul Marx, Institute for Socio-Economics, University of Duisburg-Essen, Lotharstr. 65, DE-47057 Duisburg, Germany.

Email: paul.marx@uni-due.de

\section{Funding information}

North Rhine-Westphalian Ministry of

Culture and Science

\begin{abstract}
Many observers have noticed the importance of anger in contemporary politics, particularly with reference to populism. This article addresses the question under which conditions people become angry about a specific aspect of their lives: their personal financial situation. Specifically, it asks if populist anti-elite rhetoric has a causal influence on anger and if this influence differs across socio-economic groups. The theoretical expectation is that anti-elite rhetoric allows people to externalize responsibility for an unfavorable financial situation and thereby to turn negative self-conscious emotions into anger. The argument is tested with original survey data from France, Germany, and the United States. The empirical analysis yields three main insights. First, negative emotional reactions to respondents' personal finances (and anger in particular) are surprisingly widespread in all three countries. Second, there is a pronounced socioeconomic gradient in the distribution of anger and other negative emotions. Third, and most importantly, randomly exposing participants to populist anti-elite rhetoric causes considerably higher expressed anger about one's financial situation in France and Germany, but less so in the United
\end{abstract}

This is an open access article under the terms of the Creative Commons Attribution License, which permits use, distribution and reproduction in any medium, provided the original work is properly cited.

(c) 2020 The Authors. The British Journal of Sociology published by John Wiley \& Sons Ltd on behalf of London School of Economics and Political Science 
States. This suggests a causal role of anti-elite rhetoric in stirring "pocketbook anger." This is true in particular in the middle classes. The notion that populist rhetoric reduces negative self-conscious emotions, such as shame, is not supported by the data.

\section{KEYWORDS}

anger, middle class, populism, socio-economic problems, survey experiments

\section{1 | INTRODUCTION}

Under which conditions do people become angry about their financial situation? Because feeling anger is intertwined with the motivation to identify and attack a culprit, it can fundamentally change how people connect their pocketbook to politics. Specifically, this article asks whether populist anti-elite rhetoric plays a causal role in stirring "pocketbook anger" ${ }^{11}$ and, if yes, which socio-economic groups are most susceptible to it.

These questions are important for research into how individual socio-economic problems influence political behavior and thereby might contribute to political inequality. The literature on this topic, which has grown tremendously since the Great Recession, is rather fragmented (Margalit, 2019). There are largely separate discussions about how people respond to socio-economic problems with pragmatic-materialistic responses (Margalit, 2013), withdrawal from politics (Emmenegger, Marx, \& Schraff, 2017), political radicalism (Rooduijn \& Burgoon, 2018) or out-group hostility (Gidron \& Hall, 2017).

Which of these political responses prevails under which conditions is a largely unanswered question. An emerging literature suggests, however, that part of the answer lies in peoples' varying emotional responses to socio-economic problems (Aytaç, Rau, \& Stokes, in press; Hochschild, 2016; Marx \& Nguyen, 2018; Salmela \& von Scheve, 2017; Smith, Cronin, \& Kessler, 2008; Wagner, 2014). Similar (economic) situations can be appraised by people in different ways, which leads to different emotions and (political) action tendencies (Keltner \& Lerner, 2010; Lerner, Li, Valdesolo, \& Kassam, 2015; Marcus, Neuman, \& MacKuen, 2017). Anger is particularly relevant in this context, because it has the potential to mobilize even disadvantaged or inattentive citizens to participate in politics (Aytaç et al., in press; Lamprianou \& Ellinas, 2019; Valentino, Brader, Groenendyk, Gregorowicz, \& Hutchings, 2011). Emotions and emotionalized politics can therefore contribute to reducing inequality in political engagement across socio-economic groups (Anduiza, Guinjoan, \& Rico, 2019; Marx \& Nguyen, 2018), although this might come at the cost of a more distrusting, superficial, and polarized electorate (Banks \& Valentino, 2012; Suhay \& Erisen, 2018; Webster, 2018).

This raises the question under which conditions people are likely to become angry about their economic situation as opposed to other emotional responses. While one source of variation certainly are personality differences, this article focuses on the political context. Specifically, it looks at how populist anti-elite rhetoric influences the link between socio-economic problems and negative emotions. Besides being an important phenomenon in contemporary politics, populism is interesting for the present research question, because the aggressive attribution of responsibility to political elites is one of its core elements (Busby, Gubler, \& Hawkins, 2019). Such externalization of blame is precisely what makes the difference between anger and other negative emotions (Keltner \& Lerner, 2010; Weiner, 2006).

In sum, the main hypothesis explored is that populist anti-elite rhetoric - by constructing a general culprit allows people to externalize responsibility for their financial situation and, hence, to experience anger about it. A 
second hypothesis is that the populism-attribution-anger nexus functions as a coping mechanism to reduce the more painful negative emotion of shame that results from internalized blame.

Although the primary goal is to contribute to debates about the political-behavior implications of socioeconomic problems, the article also speaks to two controversies in contemporary populism research. First, the research design allows to address the question of which socio-economic groups are receptive to populist mobilization and whether absolute or relative forms of deprivation matter more in this regard (Hameleers, Bos, \& Vreese, 2018; Mols \& Jetten, 2017; Mudde \& Rovira Kalwasser 2018; Spruyt, Keppens, \& Droogenbroeck, 2016). Second, it speaks to an emerging (but somewhat implicit) debate about whether populist parties benefit from or create negative emotions (Hochschild, 2016; Magni, 2017; Rico, Guinjoan, \& Anduiza, 2017; Salmela \& von Scheve, 2017). The results show a causal flow from populist anti-elite rhetoric to emotions so that the populism-emotions link should, at the very least, be seen as recursive (Nguyen, 2019; Rooduijn, van der Brug, \& de Lange, 2016; Wirz, 2018).

The empirical evidence is based on a survey experiment conducted in samples (representative of the population between 18 and 65 years) from three countries: France, Germany, and the United States. Randomly exposing participants to anti-elite rhetoric causes considerably higher expressed anger about one's financial situation in France and Germany, but less so in the US where a president with populist tendencies is in office. The distribution of anger across socio-economic and political groups differs somewhat between the countries. A consistent finding is, however, that it is not so much the lower classes but rather the middle classes that respond to anti-elite messages with pocketbook anger.

\section{2 | ANTI-ELITE MOBILIZATION AND POCKETBOOK ANGER}

Emotions are embodied mental processes triggered by a stimulus. This process involves cognitive appraisals along several dimensions (valence, goal relevance, novelty, fairness, agency, and intentionality), physiological arousal and action tendencies. Together these components form a subjectively experienced emotion (Scherer \& Moors, 2019). Anger is associated with events appraised as undesirable and caused by others. Its intensity should rise with goal relevance (e.g., if self-esteem is involved), perceived unfairness and intentionality (Hegtvedt \& Parris, 2014; Smith et al., 2008; Weiner, 2006). The corresponding action tendency is to approach (e.g., restoration of justice, retribution, holding culprit responsible). Other-blame and approach motivation differentiate anger from negative self-conscious emotions, in particular shame, that come with internal attribution and withdrawal tendencies (Keltner \& Lerner, 2010). In line with this reasoning, it has been shown to foster political efficacy and participation and the tendency to punish incumbents (Aytaç et al., in press; Jasper, 2018; Lamprianou \& Ellinas, 2019; Marcus et al., 2017; Valentino et al., 2011; Wagner, 2014).

Note that I do not claim causal precedence for cognitive appraisals in general, a claim that would not be in line with neuroscientific evidence on the emotion process (Barrett, 2017). But the argument developed below does turn on the idea that political discourses can stir pocketbook anger through a reappraisal of agency, fairness, and intentionality.

\section{1 | Emotional consequences of (lacking) money}

Earning a subjectively sufficient amount of money-or not-is an intensely emotional matter. For some people, negative emotions result from existential economic threats, but the main reason in wealthy capitalist societies is that money and the goods it can buy are status markers and ingredients for social approval (Cohen, Shin, \& Liu, 2019; Collins, 2004; Frank, 2007; Turner, 2015). Feeling deprived of status is a painful experience (Kemper, 2017; Ridgeway, 2014; in a literal sense: Eisenberger, 2015). If people internalize responsibility for this deprivation, 
they will experience a mix of negative self-conscious emotions, shame in particular, and tend to withdraw from social and political life (Lewis, 2016; Tangney, Stuewig, \& Mashek, 2007). If people identify an external cause, the experience of status deprivation has all ingredients for intense anger, which motivates action against this cause. This pocketbook anger is not restricted to short episodes but might sediment over time into a "moral emotion." In this case, it would be more accurate to speak of righteous anger, indignation, or possibly hate (Jasper, 2018, pp. 145-151).

Theoretically, negative emotions are not restricted to the experience of "objective" poverty. They can also result from frustrated attempts to "keep up with the Joneses." Status is relative to milieu-specific reference points (Kemper, 2017). Therefore, nothing speaks against pocketbook anger or shame in the middle class (Mols \& Jetten, 2017).

\section{2 | Political discourses and negative pocketbook emotions}

Capitalist societies are often portrayed as benefitting from a "neoliberal" ideology of self-responsibility. Discourses based on this ideology individualize and moralize economic failure, while they idealize economic success (Boltanski \& Chiapello, 2005; Lamont, 2019; Sennett, 2006). In short, they foster internal attribution and are conducive to shame (Salmela \& von Scheve, 2017; Walker, 2014). The response should be self-deprecation/improvement rather than political action. In electoral research, voters are often seen as reluctant to blame governments for personal economic problems in this culture (Kiewiet \& Lewis-Beck, 2011; Sniderman \& Brody, 1977). However, the specific political context might matter.

Socio-economic problems are more likely to become politicized if they are perceived as collective, externally caused, and unfair-appraisals that should be accompanied by (moral) anger (Aytaç et al., in press; Marx, 2016; Smith et al., 2008). Several ideologies and discourses aim at constructing such mobilizing appraisals, for example, socialism. In recent years, populism has been particularly successful. Although it does not always address economic grievances explicitly, a defining feature of populism is the portrayal of social elites as selfish and intentionally harmful to ordinary people (Busby et al., 2019; Hameleers, Bos, \& Vreese, 2017; Mudde \& Rovira Kaltwasser, 2018). This discourse constructs a generalized externalization of blame, which people can apply to many problems, including their pocketbook. Moreover, socio-economic comparisons are usually at least implied in populist discourses. This can take the form of defending "hard-working" citizens against free-riders, criticizing redistribution to minorities, addressing the waste of tax money, or sometimes full-blown indignation about economic inequality and globalization (Cramer, 2016; Gidron \& Hall, 2017; Hochschild, 2016; Lamont, Park, \& AyalaHurtado, 2017; Mols \& Jetten, 2017; Schumacher \& van Kersbergen, 2016). It thus seems clear that populists try to mobilize voters through stirring anger, including anger about socio-economic outcomes.

\subsection{Populism and negative emotion: the psychological mechanism}

The link between negative emotions and populist appeal is an emerging topic in the literature, but the mechanism is not always clear. One version of the argument is that populists benefit from, express, or channel voters' pre-existing anger (Rico et al., 2017). Magni (2017) draws, for instance, a causal chain from the 2008 crisis over attribution and anger to populist voting. Vasilopoulos, Marcus, Valentino, and Foucault (2019) show that anger resulting from the 2015 Paris Terror Attacks predicted voting for the radical right. Salmela and von Scheve (2017) argue that socio-economic problems can produce diffuse anger that results from repressed shame and that can be directed by radical right-wing parties at concrete targets. Other contributions put stronger emphasis on political agency. They argue that populist rhetoric causes external attribution and anger or that the link between anger and populism is recursive (Busby et al., 2019; Hameleers et al., 2017; Marx \& Nguyen, 2018; Nguyen, 2019; Rooduijn 
et al., 2016; Wirz et al., 2018). However, anger is rarely used as a dependent variable in these studies (but see Wirz, 2018).

Commenting on the link between emotions and populism, Jost (2019, p. 710) has recently called for more attention to "nonobvious psychological mechanisms-such as denial, projection, repression, and affect displacement." An example for such a mechanism comes from Hochschild (2016, ch. 15), who contemplates the possibility that populist agency is instrumental in transforming pre-existing negative emotions of depression and shame into more enjoyable collective emotions, including anger. Building on this intuition, I argue that people in capitalist societies, who experience some form of relative socio-economic deprivation, harbor a mix of negative prepolitical emotions; some idiosyncratic combination of anxiety, guilt, shame, anger, sadness, and envy. Among these, self-conscious emotions that are associated with internal attributions are the more painful ones and people should be strongly motivated to avoid them (Lewis, 2016; Scheff \& Retzinger, 1991; Tangney et al., 2007). The externalization of blame is the primary way to achieve this (Stuewig, Tangney, Heigel, Harty, \& McCloskey, 2010; Turner, 2015). However, as mentioned above, externalization is to some extent constrained by cultures idealizing meritocracy and self-responsibility. If people in such a situation are exposed to populist anti-elite discourse, it means that they are offered a cognitive reappraisal that plausibly attributes responsibility to an external cause and that seems to be legitimized by the support of many fellow citizens. This should be intuitively appealing and cause a shift of the negative emotion mix towards the least unpleasant one: anger, particular in its collective form. In the real world, this implies that relatively deprived voters might intuitively select into anti-elite rhetoric. But here I focus on the second implication that exposure to anti-elite rhetoric can increase anger about one's financial situation (Hypothesis 1). Anger, of course, presupposes some form of negative pocketbook evaluation. As discussed below, the assumption is that many people in different socio-economic groups can find some aspect of their financial situation to be frustrated about, for instance through unfavorable social comparisons.

The argument suggests anger to serve as a coping mechanism for other negative pocketbook emotions. In fact, coping through re-attribution is well established in the psychological literature. As summarized by Tangney et al. (2007, p. 352):

shame and anger go hand in hand. Desperate to escape painful feelings of shame, shamed individuals are apt to turn the tables defensively, externalizing blame and anger outward onto a convenient scapegoat. Blaming others may help individuals regain some sense of control and superiority.

Following this reasoning, anger induced through anti-elite rhetoric might serve, to borrow Hochschild's (2016, p. 226) metaphor, as an "antidepressant." This points to the possibility that exposure to anti-elite rhetoric decreases shame about one's financial situation (Hypothesis 2). This hypothesis comes close to the argument by Salmela and von Scheve (2017) about repressed shame as a basis for populist mobilization. The main difference is that in their argument, coping with shame occurs prior to discourse exposure, whereas I emphasize in addition the direct causal role of anti-elitism in shame coping (see Marx \& Nguyen, 2018 and Spruyt et al., 2016 for related arguments and Jasper, 2018 for an overview of analogous strategies in social movements).

\subsection{Who becomes angry?}

So far, socio-economic problems and deprivation were described in deliberately generic terms. Indeed, the argument can be applied for many different subjective problems, as long as the content of a political discourse allows plausible externalization of responsibility. Populism often denies this to the poorest in society. Particularly if they belong to minorities or do not work, they actually become scapegoats in some populist narratives (Lamont et al., 2017; Mols \& Jetten, 2017; Schumacher \& van Kersbergen, 2016). External attribution and anger could actually be easier to instill in members of the (lower) middle class who belong to the ethnic majority, because 
it is easier for them to identify with populists' stylized "people." And although it is difficult to identify a typical populist electorate across countries (Stockemer, Lentz, \& Mayer, 2018), it is often argued that populist parties have electoral strongholds in the lower middle class rather than the absolute bottom of the income distribution (Golder, 2016).

While the default amount of negative pocketbook emotions should decline with income, the middle class should be by no means immune (Lamont, 2019). Research on positional consumption suggests that income inequality and ensuing status competition are considerable stressors for middle-class families (Frank, 2007; Winkelmann, 2012). Relatedly, it has been argued that negative emotional reactions are particularly intense if relatively high but precarious socio-economic status becomes threatened (Mols \& Jetten, 2017).

Beyond these considerations, the present article refrains from making a general argument about whether people in the lower or middle classes are more prone to respond to populist rhetoric with anger. Existing research offers little guidance on this question and it likely depends on the social and political context. Consequently, an inductive approach is adopted for this aspect.

\section{I SURVEY EXPERIMENT ON POPULISM AND POCKETBOOK EMOTIONS}

Hypotheses 1 and 2 are tested in a survey experiment conducted in November and December 2018 in three countries. For each country, about 1,500 participants aged 18 to 65 years were sampled from YouGov's online panel. YouGov claims representativeness, but common sense and research in survey methodology (Couper, 2017) cast doubt on this claim. It is reasonable to expect that opt-in recruitment compared to random sampling introduces bias in unobserved characteristics. It cannot be ruled out, for example, that politically engaged as opposed to apathetic citizens are more likely to select into the panel and that the former are more likely to make external attributions and to experience anger. That said, for experimental research such panels provide an affordable compromise of internal and external validity that allows at least a tentative generalization of the findings. For the present purpose, they moreover provide the indispensable variation in socio-economic background.

\section{1 | Case selection and contexts}

The experiment was conducted simultaneously in France, Germany, and the US. The goal of including several countries is not to isolate the effect of a specific variable, but to provide some background variation within the universe of advanced capitalist democracies. This anticipates unclear replicability as a frequent criticism of experimental research (Sniderman, 2018) and might form the basis for comparative hypotheses.

The three countries differ on a number of dimensions. They include, for instance, a presidential, semi-presidential, and parliamentary democracy, two- and multi-party systems, liberal and coordinated market economies, advanced and residual welfare states and different degrees of economic inequality. Also, the particular form and intensity of populist politics differ. In short, France is a case with a relatively long tradition of populist parties both on the political left and right. Populism's influence in French society was illustrated by the strong showing of populist candidates in the 2017 presidential election and the violent Gilets jaunes protests that erupted during the data collection in November 2018. Populism is weaker in Germany where only the 2015 "refugee crisis" led to the emergence of a radical right-wing party on the national level and where left-wing populism is not strongly developed. The US is the only case with a government that could be described as populist. Although its electoral system usually keeps populist challengers out, the US has a long history of populist rhetoric inside the main parties, from third candidates and in the media. 


\section{2 | Experimental design}

The experimental design closely follows Marx and Nguyen (2018). As in their study, the goal is to activate populist anti-elite rhetoric. This is done by randomly exposing half of the sample (prior to emotion measurement) to three survey items, for which they can indicate their (dis)agreement on Likert scales from one to five. The control group receives the anti-elite statements after the emotion measurement. The statements are:

"Politicians often lie to get elected."

"Politicians are mainly interested in their careers and not in the good of the country."

"The politicians in [Paris/Berlin/Washington] have abandoned ordinary people."

These statements reflect the typical anti-elite component of populist rhetoric, but are far from extreme versions of this criticism. The goal is to mentally activate a "populist lens" on one's pocketbook that, according to Hypothesis 1 , should elicit anger by facilitating external attribution. The statements deliberately do not include direct references to specific ideologies or socio-economic problems. While the latter would arguably make treatment effects more likely, the chosen formulation allows assessing if participants translate general populist attributions into appraisals of their pocketbook situation.

A weakness of the design should be acknowledged. This way of mentally activating populism as an interpretative frame obviously draws on real-world experiences that experimental and control group share. The control group is therefore "contaminated" with exposure to populist discourse whose duration and intensity depends on the country. The statements will hardly provide a surprising or new framework for thinking about politics, so that any treatment effect should be interpreted as resulting from variation in situational salience of populism. While this is unfortunate, it is hard to avoid in research on relevant real-world phenomena. Moreover, it should raise the possibility of bottom and ceiling effects and hence stack the cards against significant treatment effects.

\subsection{Measuring emotions}

The primary dependent variable is anger (Hypothesis 1), complemented with shame (Hypothesis 2). Following widespread practice, emotions are measured through self-reports based on emotion words. As advocated by Marcus et al. (2017), participants are asked to move sliders on scales between low ("Not at all...") and high intensity ("Extremely...") of the respective emotion (from zero to hundred). Anger is measured, for example, with the words "angry," "irritated," and "annoyed." The instructions read as follows:

We would like to ask you to take a moment and think about your personal financial situation. What we mean by that is how difficult or easy you find it to make ends meet with your budget and to afford the things you want. If you think about your personal financial situation: how does that make you feel? Please choose the location that shows how you feel. You can afterwards move the slider to the left or the right to change the location.

Note that nothing in the formulation indicates a link to politics. Moreover, the wording has a "bottom-up" character because rather than specifying particular socio-economic problems or benchmarks, it leaves it entirely to respondents what standards they use to assess their financial situation. While "making ends meet" probably has a connotation of more existential problems, an inability to "afford things you want" could apply to just anybody. The downside of this 
flexible approach is lacking control over and information about respondents' considerations. While negative emotions should imply some form of dissatisfaction, the thoughts causing pocketbook anger or shame remain a black box.

The emotion words are chosen from the modified Differential Emotions Scale (mDES; Fredrickson, 2013) and translated into French and German (Table A1 in the Appendix). To avoid overwhelming respondents and out of cost considerations, the number of emotion items is restricted to ten. The emotions that are central to the hypotheses, anger and shame, are measured with three items. In addition, to account for the possibility that other negative emotions are involved, sadness and fear are measured with two items.

A comment is necessary on shame measurement, which is not straightforward. The main reason is that expressing shame is stigmatized and, hence, shameful itself. As Scheff and Retzinger (1991) show, people therefore usually use indirect verbal markers to express it. Against this background, mDES shame words ("ashamed," "humiliated," "disgraced") are not perfect for the present context. Few people would arguably use such strong language to describe financial situations. "Humiliated" and "disgraced" are therefore replaced with "embarrassed" and "dissatisfied with myself." The former technically is a different emotion (Lewis, 2016), however, with fuzzy boundaries in colloquial speech. The latter is a verbal marker that seems appropriate to express milder forms of pocketbook-induced shame.

All emotion domains have satisfactory Cronbach's alphas in each of the countries (Table A1), so that the respective arithmetic mean is used in the analyses. However, it has to be acknowledged that the method did not work well in differentiating between negative emotions. The correlations of anger with the other negative emotions is high in each of the three countries, ranging between 0.65 and 0.86 . Moreover, exploratory factor analyses (not shown) yield one-factor solutions in each of the countries. This issue, to which I will return in the final discussion, is a problem in particular for Hypothesis 2 which turns on the notion that anti-elite rhetoric can change the negative emotion mix.

\subsection{Operationalizations of socio-economic groups}

The theory section raised the question in which socio-economic groups the susceptibility to respond to anti-elite rhetoric with anger can be observed. Hence, treatment effects could be moderated by respondents' financial situation. The analyses rely on natural variation in socio-economic position, which, to assess robustness, is operationalized in three ways (in line with the theoretical considerations, categorical moderators are used that do not assume a linear relationship). First, to capture its subjective dimension, a question is borrowed from the European Social Survey: "Which of the following statements comes closest to how you feel about your household's income nowadays?" The four answer options are "Living comfortably on present income," "Coping on present income," "Finding it difficult on present income," and "Finding it very difficult on present income."

Second, as an objective measure, household income is included by (a) deriving a pseudo-linear income variable by assigning the midpoint of YouGov's country-specific income bands; (b) dividing this variable by top-coded household size (as a crude equivalence scale) and (c) dividing the samples in quintiles.

Third, as a global assessment of socio-economic position, people are asked a typical "social-ladder" question: "There are people who tend to be towards the top of our society and people who tend to be towards the bottom. Where would you place yourself on the following scale nowadays?" Possible answers range from one ("Bottom of our society") to ten ("Top of our society"). Because the goal is to study effects of distinct positions in the class hierarchy, rather than linear effects of status, the variable is broken down into five categories, each comprising two scale points.

While all these operationalizations have blind spots if applied in isolation, together they should go a long way in capturing relevant aspects of socio-economic positions in post-industrial societies. The two subjective moderators were measured after the treatment (which, however, only influenced the question order). Income is a background variable provided by YouGov. As can be seen in Table A2, there is no post-treatment bias. 


\section{5 | Mean differences in negative pocketbook emotions}

Figure 1 presents anger and shame distributions across countries and experimental conditions. Eyeballing these distributions immediately suggests strong treatment effects in France and Germany. In France, the proportion of very angry respondents grows considerably after receiving the treatment. In Germany, there is a decline of respondents with very low anger and a clear growth of respondents with (very) high anger (although from a lower level compared to France). Differences for anger in the US and for shame in all three countries appear modest or non-existent.

$T$-tests between control and treatment groups confirm these impressions (Table 1). The mean difference for anger is 9.3 in France and 8.7 in Germany and is highly significant in both cases. In the US, the difference is only 1.9 and insignificant. For shame, there is a significant but small difference in the pooled sample, which seems entirely driven by France.
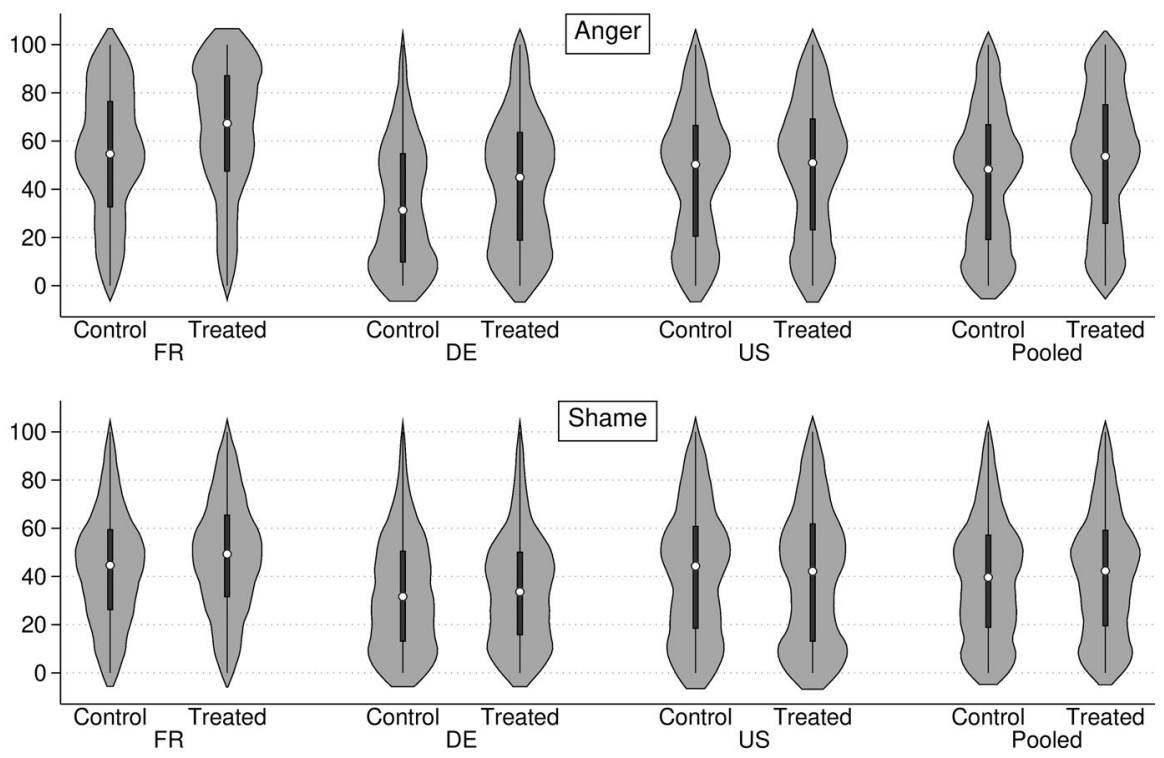

FIGURE 1 Distribution of anger and shame by country and experimental condition.

Note: Grey: kernel density, white dot: median; thick line: interquartile range, thin line: upper to lower adjacent values

TABLE 1 Mean differences for anger and shame by country

\begin{tabular}{|c|c|c|c|c|c|c|}
\hline & \multicolumn{3}{|l|}{ Anger } & \multicolumn{3}{|l|}{ Shame } \\
\hline & Control & Treated & Mean diff. & Control & Treated & Mean diff. \\
\hline \multirow[t]{2}{*}{ FR } & $M=54.3$ & $M=63.6$ & 9.3 & $M=44.1$ & $M=48.1$ & 4.0 \\
\hline & $S D=28.4$ & $S D=28.0$ & $p<.001$ & $S D=24.2$ & $S D=24.7$ & $p=.002$ \\
\hline \multirow[t]{2}{*}{$\mathrm{DE}$} & $M=35.0$ & $M=43.7$ & 8.7 & $M=33.6$ & $M=35.7$ & 2.2 \\
\hline & $S D=27.5$ & $S D=28.5$ & $p<.001$ & $S D=24.4$ & $S D=24.2$ & $p=.099$ \\
\hline \multirow[t]{2}{*}{ US } & $M=46.1$ & $M=48.0$ & 1.9 & $M=42.0$ & $M=41.2$ & 0.9 \\
\hline & $S D=28.3$ & $S D=28.7$ & $p=.207$ & $S D=27.6$ & $S D=28.9$ & $p=.557$ \\
\hline \multirow[t]{2}{*}{ Pooled } & $M=45.1$ & $M=51.8$ & 6.7 & $M=39.9$ & $M=41.7$ & 1.8 \\
\hline & $S D=29.1$ & $S D=29.7$ & $p<.001$ & $S D=25.8$ & $S D=26.5$ & $p=.022$ \\
\hline
\end{tabular}

Note: Mean diff. $=$ Mean treated - Mean control. $P$-values based on two-tailed $t$-tests. 
In passing, it is also worth looking at the other two emotions. In France, there are highly significant mean differences for sadness (7.0) and fear (7.1) that are smaller than for anger. In Germany, there is a significant effect only for sadness (4.2). In the US, neither variable shows a significant difference.

In sum, the treatment seems to be effective in generating negative pocketbook emotions in France and Germany, but not in the US. The patterns lend some initial support to Hypothesis 1. Hypothesis 2, however, does not perform well on this level of analysis. The conjectured negative effect could not be observed in any country.

\subsection{Treatment effects by socio-economic group}

As indicated earlier, treatment effects can be expected to differ across socio-economic groups. Figure 2 therefore shows predictions of anger levels by experimental condition in these groups (based on regressions of anger on
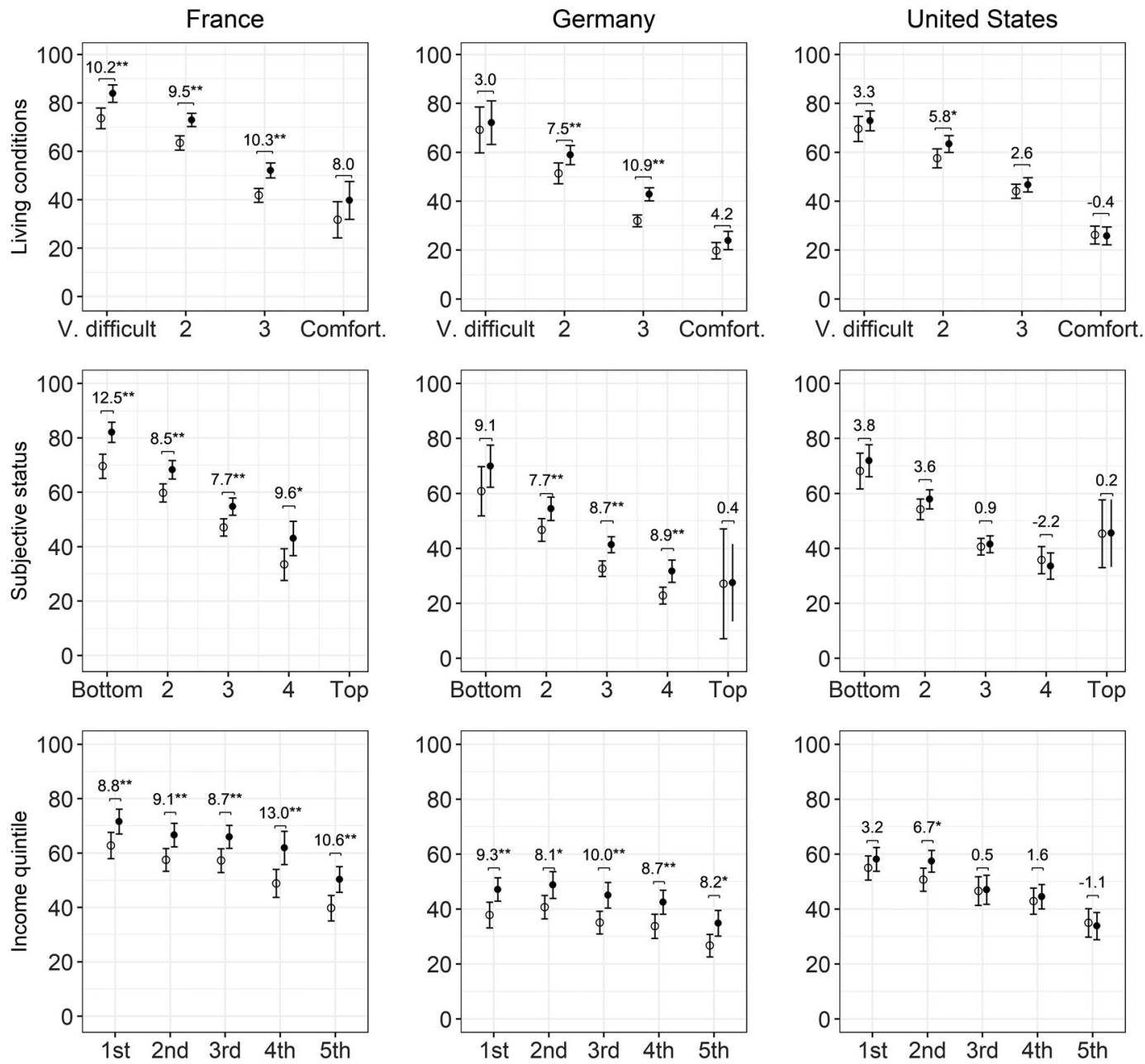

\section{Control group}

Anti-elite treatment

FIGURE 2 Average pocketbook anger by country, socio-economic group and experimental condition with $95 \%$ confidence intervals.

Note: Labels in the graph present marginal effects of the treatment $\left({ }^{*} p<.05 ;{ }^{* *} p<.01\right)$. Category "Top" in

"Subjective status FR" dropped because of low cases numbers $(n=9)$ 
the treatment indictor, the respective categorical group variable and their interaction). The marginal effects of the treatment by group are included as labels (see also Figure A1).

A first observation is that for all countries and variables, there is a clear socio-economic gradient. Unsurprisingly, the gradient is less clear for income quintiles, which is a rather crude measure and, compared to the subjective indicators, further away in the causal chain producing pocketbook anger. The fact that pocketbook anger does show the expected distribution should increase trust in the variable. Moreover, I would argue that the magnitude of the differences is important descriptive information in its own right. It suggests that citizens with unfavorable socio-economic positions experience considerable anger (and probably tend to externalize blame), even in the control group. Again, it might be possible that exposure to anti-elite rhetoric outside the experiment has contributed to this (which would lead to an underestimation of its effect in the experiment).

Turning to treatment effects by socio-economic group, there are some differences across contexts. But a general observation is that treatment effects do not decrease linearly with socio-economic position and that anger effects are far from being restricted to the bottom segments. In most cases, treatment effects do not differ significantly across groups. ${ }^{2}$ In France, they are actually strikingly homogenous. The only exceptions are high subjective positions (interestingly, French participants were reluctant to place themselves in the two highest status categories; they only comprised nine cases and had to be dropped from the analysis). Hence, it seems that there is considerable potential for pocketbook anger across society and that the emotion measurement is flexible enough to capture the probably quite different sources of anger in the middle and the lower classes. In this context, it should be borne in mind that populism in France is spread across the political spectrum. This means that it could be easier to link the generic anti-elite rhetoric used in the experiment to different economic grievances, such as poverty or excessive taxation.

In Germany, treatment effects are only significant in the middle segments on the subjective scales (although the differences to the bottom segment are insignificant) and homogenous across income quintiles. Hence, also in Germany the middle class shows a clear tendency to respond to anti-elite rhetoric with pocketbook anger. The lack of significance in the lower segments of the subjective scales could partly be explained by lower cases numbers.

The finding regarding the middle class also holds for the US, but in a narrower and less consistent way. Here, we only observe a significant treatment effect among respondents in the second lowest category of subjective living conditions ("Difficult") and in the second lowest income decile. Hence, in the US it is only the lower middle class that shows some anger response.

In sum, there are some country differences in the socio-economic profile of respondents susceptible to pocketbook anger. Overall, the anger response is strikingly uniform in France and Germany and mostly absent in the US. The consistent finding across countries is that the lower middle class expresses more anger after having been exposed to populist rhetoric (with significant effects in eight out of nine models).

The equivalent of Figure 2 for shame as a dependent variable is shown in the Appendix (Figure A2). Taken together, there is no support for Hypothesis 2 in it. There are only few significant effects and among those few, most are clearly smaller in size than effects for anger. In fact, there is only one significant effect in the expected (negative) direction.

As a robustness check, Figure A1 in the Appendix compares marginal effects with and without control variables. This is relevant because the moderators are non-experimental and could capture unobserved heterogeneity. To reduce such potential bias, additional models control for age (square), dummies for gender, university, degree, and employment, self-placement on the left-right scale, political interest, residence in cities and country-specific region dummies. As can be seen from Figure A1, the marginal effects do not differ meaningfully across models with and without control variables. In a second step, responses to the anti-elite statements in the treatment are controlled for additionally. In many cases, effects become slightly stronger when anti-elite attitudes are controlled for, but the overall picture changes little.

Finally, one might ask if the socio-economic categories emphasized in this article are the only relevant comparison. An additional possibility-that can only be explored briefly here-is that political orientations moderate 

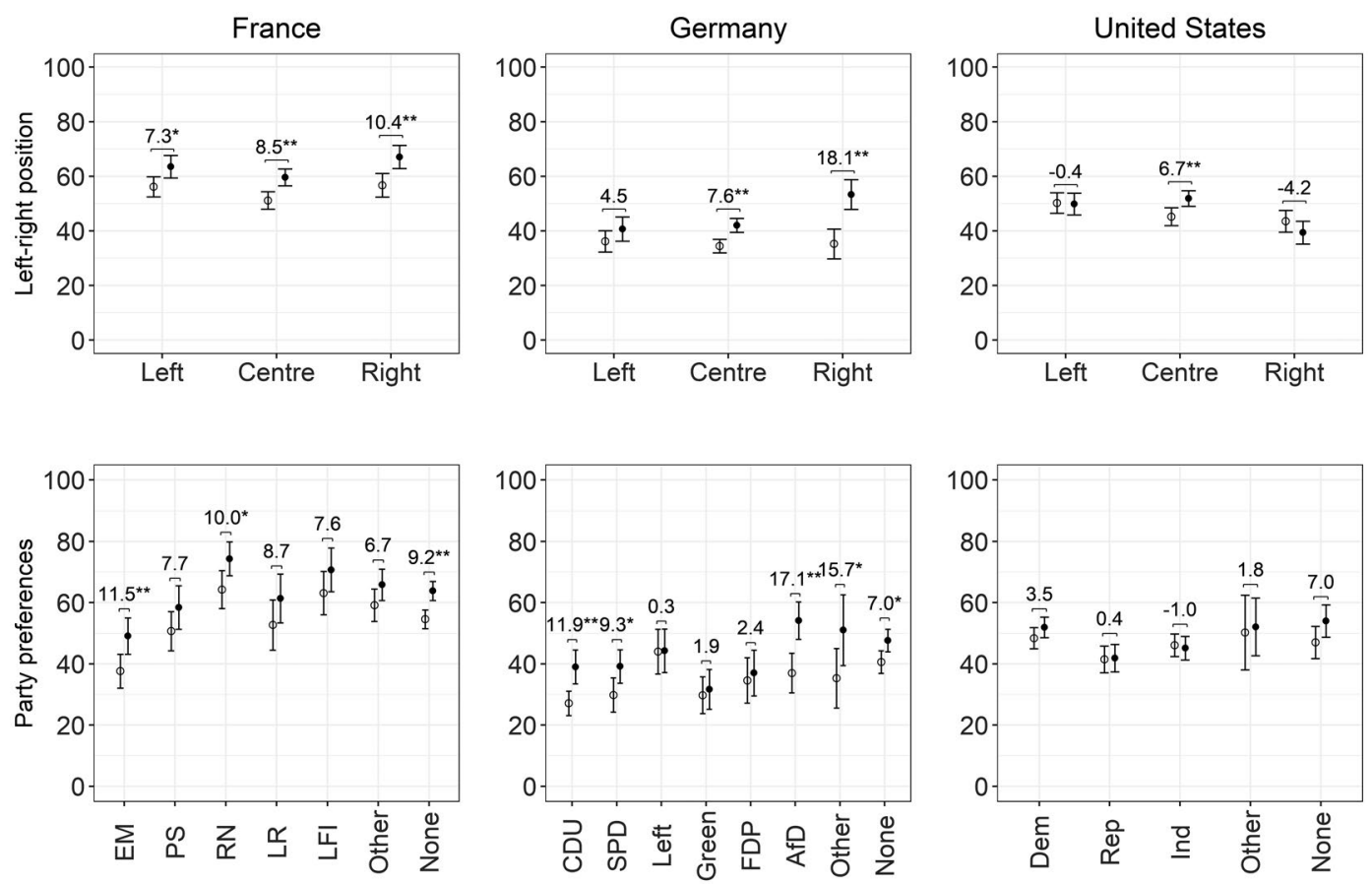

\section{Control Anti-elite treatment}

FIGURE 3 Average pocketbook anger by country, political preference and experimental condition with $95 \%$ confidence intervals.

Note: Labels in the graph present marginal effects of the treatment $\left({ }^{*} p<.05 ;{ }^{* *} p<.01\right)$. Left-right categories recoded from continuous 0-10 scale (Left: 0-3; Centre: 4-6; Right: 7-10). Party preferences refer to (a) France: Vote choice in first round of 2017 legislative election; (b) Germany: Vote choice in 2017 federal election; (c) USA: Party identification

the treatment. Figure 3 presents treatment effects by political leaning (left-right scale and party preferences, see figure note for details). It shows that there are indeed important differences. A result that stands out is that in Germany, voters of the right-wing populist Alternative für Deutschland (AfD) are extremely susceptible to the anti-elite frame. They show a highly significant treatment effect of around 17 (voting for "Other" parties and rightwing ideology have equally large effects in Germany). At the same time, AfD voters' bottom line anger is much lower than among French voters of Rassemblent National (who show a smaller but still significant treatment effect). A reason could be that German voters have not (yet) internalized to the same extent the still fairly recent anti-elite rhetoric of the radical right. Another striking finding is the clear treatment effect among voters of the traditional German center parties (CDU and SPD). This bolsters the interpretation that the middle of society is not immune to pocketbook anger. Similar observations can be made for voters of En marche in France or with a centrist ideology in the US (where there are, again, few significant effects). Finally, it is noteworthy that respondents who abstain or do not support any party ("none") tend to respond with anger. This could point to a mobilizing effect of anti-elite rhetoric among the apathetic.

Treatment effects by ideology show a similar pattern. In France, there are significant effects across the ideological spectrum. In Germany, there is a particularly strong effect on the political right, which is consistent with the observation for AfD voters. Interestingly, centrist voters in the US show a significant effect. Given the null results in the breakdown by party preferences, it is difficult, however, to provide a firm interpretation of this finding. Overall, political commitments appear to be more important moderators of the treatment effects than socio-economic position. 


\section{4 | DISCUSSION}

Taken together, the analyses support Hypothesis 1. Anti-elite rhetoric in many cases has a causal influence on pocketbook anger. Regarding the research question of who becomes angry, there was rather consistent evidence for anger susceptibility in the (lower) middle classes. This fits into narratives of a "shrinking," "anxious," or "squeezed" middle (e.g., Mols \& Jetten, 2017). But it should also be borne in mind that respondents at the bottom of the distribution already expressed much stronger anger in the control group, a phenomenon that deserves attention in future research.

A caveat in the present analyses was the strong correlation between negative emotions that are conceptually distinct. It might be that this relates to a weakness of measuring emotions with verbal markers whose meaning depends on the context. It could also be specific to the present topic of socio-economic status. Respondents might find it difficult (or might not be sufficiently motivated) to differentiate their complex pocketbook-related emotions in the context of a survey. The choice only to include negative emotions might have facilitated an undifferentiated response pattern even further. Interestingly, Aytaç et al. (in press) in a related study made a similar observation when their blame treatment simultaneously (and counter-intuitively) triggered anger and guilt among the unemployed (see their footnote 7). Finally, the shame mechanism might apply only to cases of intense socio-economic problems that were not captured by the rather abstract measurement in this article. ${ }^{3}$ Generally, more research on negative pocketbook emotions is necessary. For this analysis, the strong correlations might raise concerns about whether anger really captured negative valence. However, as shown above, for anger there were considerably stronger and more consistent effects than for any other negative emotion. This suggests that the results are, to some extent, unique for anger.

As was to be expected, treatment effects on pocketbook anger differed across countries. It is tempting to interpret these differences in light of the countries' variants of real-world populism, but there certainly are many factors at play. In France, where the data collection coincided with the populist yellow-vest riots, where mainstream parties imploded in the 2017 elections and where populist mobilization is spread across the left-right continuum, treatment effects could be observed in most socio-economic groups. Again, it seems plausible that in this context respondents were relatively free to project a diverse array of economic problems on the abstract anti-elite attribution. In Germany, populism's arrival at the core of the party system is more recent and is mostly associated with the radical right. This could contribute to a context where it is easier for the middle class than for the most disadvantaged citizens to use anti-elitism as a re-attribution device.

The US was the case with the weakest treatment effects. It is not unreasonable to speculate that this might have something to do with the populist tendencies of the incumbent president. First, populists in power could simply weaken the treatment, because respondents get confused about whom exactly the label "Politicians in Washington" refer to. Second, the process of re-attribution gets complicated, because even supporters of populism have to ask themselves to what extent the "establishment" or the current populist government should be blamed. Third, populist discourses might lose their quality as empty signifiers if they are associated with policy approaches, such as tax cuts for the wealthy or protectionism for specific industries. Fourth, populist rhetoric might be so prevalent in political discourses that respondents show weaker responses to it than elsewhere. To verify these speculations, we would have to know more about emotion and attribution dynamics among supporters of populists who move into office. It also should be mentioned that the non-findings for the US could be explained by cultural factors. It is often argued to be a society with comparatively strong commitment to economic self-reliance (Lamont, 2019). This could be an independent cultural factor weakening the readiness to externalize responsibility (Sniderman \& Brody, 1977).

Finally, the non-finding for shame merits discussion. As already explained in the beginning, shame is not easy to measure. This is certainly true for the type of shame the present argument emphasizes: the largely unconscious self-degradation through accepting economic failure as one's own fault. It might be that the used shame measurement of simply asking people about it is too naive. Of course, it might very well be that the argument about populism as shame coping is flawed. However, given the methodological limitations of the present paper, alternative (and probably more indirect) measures should be applied before dismissing it. This is even more so as 
the high baseline levels of anger could be interpreted as suggestive evidence that some shame repression along the theorized lines has taken place already in real-world politics.

\section{5 | CONCLUSIONS}

This article has three messages that future research on the micro-political implications of socio-economic problems should take into account. First, people's pocketbook is a deeply emotional matter. Far into the middle classes, many respondents attached intense negative emotions to their financial situations. This does not necessarily keep them from considering material aspects, but it suggests that such cognitive factors have to compete with powerful affective influences. Given what we know from the psychology of emotions, this can have profound moderating effects on behavior. Anger might be precisely what makes the difference between mobilizing and de-mobilizing tendencies resulting from socio-economic problems (Aytaç et al., in press). This potential need not be cast in a positive light, because anger could simultaneously foster problematic tendencies towards harsher attitudes and polarization (Banks \& Valentino, 2012; Suhay \& Erisen, 2018; Webster, 2018). Second, the findings suggest that discursive contexts can influence the political meaning of socio-economic problems. Studying the interplay of discourse, emotion, attribution, and political behavior certainly is a relevant avenue for research in this area. Antielite populism arguably is only one example for a discourse that matters in this regard. And even for populism, this article has only started to tease apart the mechanisms through which it influences the emotional dynamic of personal finances. Third, we should not treat socio-economic position as a linear construct and assume that people in the absolute bottom are the most politically alienated. Rather, this research reinforces worries about the political integration of relatively deprived middle classes in advanced capitalist societies. Of course, pocketbook anger does not amount to political alienation and its behavioral manifestations still have to be established. However, it does seem plausible that the responsiveness to the treatment in this study does indicate considerable economic frustration paired with a willingness to blame politicians for it. How the middle class links current and anticipated economic grievances to politics is a critical question-scientifically and socially. An important gap in the present article is that such grievances were not measured directly. Future research should zoom in on this aspect and establish what exactly are the sources of pocketbook anger in different socio-economic groups.

Finally, the presented findings bear relevance for populism research as well. Mudde and Rovira Kaltwasser (2018) have recently argued that debates about socio-economic determinants of populist appeal have reached an impasse. This is arguably the consequence of overly structuralist or simply vague conceptions of socio-economic factors (as illustrated by the losers-of-globalization debate). Departing from the psychological functions of jobs, money, and consumption might be a way out. If we take peoples' subjectivity seriously, we are forced to acknowledge that material rewards have no motivational force per se. Rather, they are linked to behaviors through complex, dynamic, and relational emotion processes. We are only beginning to understand how populists can benefit from and shape these processes.

\section{ACKNOWLEDGMENTS}

I gratefully acknowledge very helpful exchanges about this research with Sabina Avdagic, Bert Bakker, Christoph Nguyen, Nelson Ruiz, David Rueda, Gijs Schumacher, and Fieke Wagemans. Previous versions were presented in workshops and talks at the Paris School of Economics, University of Oxford, University of Sussex, and University of Bochum, during which I received many valuable comments. The article is part of the research project "The influence of socio-economic problems on political integration" funded by the North Rhine-Westphalian Ministry of Culture and Science.

\section{DATA AVAILABILITY STATEMENT}

The data that support the findings of this study are available from the corresponding author upon request. 


\section{ORCID}

Paul Marx iD https://orcid.org/0000-0003-4310-9228

\section{NOTES}

${ }^{1}$ Pocketbook anger is a neologism inspired by the concept of "pocketbook voting" in the economic voting literature. I use it as a shorthand for anger about one's personal economic situation.

2 The statistical comparison of groups is omitted for space reasons. The absence of treatment heterogeneity is documented by the strongly overlapping confidence intervals in Figure A1.

${ }^{3}$ Among respondents indicating (very) difficult living conditions, all emotions still load on a single factor and their correlations remain substantial.

\section{REFERENCES}

Anduiza, E., Guinjoan, M., \& Rico, G. (2019). Populism, participation, and political equality. European Political Science Review, 11(1), 109-124.

Aytaç, S. E., Rau, E. G., \& Stokes, S. (in press). Beyond opportunity costs: Campaign messages, anger and turnout among the unemployed. British Journal of Political Science.

Banks, A. J., \& Valentino, N. A. (2012). Emotional substrates of white racial attitudes. American Journal of Political Science, 56(2), 286-297.

Barrett, L. F. (2017). The theory of constructed emotion: An active inference account of interoception and categorization. Social Cognitive Affective Neuroscience, 12(1), 1-23.

Boltanski, L., \& Chiapello, E. (2005). The new spirit of capitalism. London, UK: Verso.

Busby, E. C., Gubler, J. R., \& Hawkins, K. A. (2019). Framing and blame attribution in populist rhetoric. Journal of Politics, 81(2), 616-630.

Cohen, D., Shin, F., \& Liu, X. (2019). Meanings and functions of money in different cultural milieus. Annual Review of Psychology, 70(1), 475-497.

Collins, R. (2004). Interaction ritual chains. Princeton, NJ: Princeton University Press.

Couper, M. P. (2017). New developments in survey data collection. Annual Review of Sociology, 43(1), 121-145.

Cramer, K. J. (2016). The politics of resentment: Rural consciousness in Wisconsin and the rise of Scott Walker. Chicago, IL: University of Chicago Press.

Eisenberger, N. I. (2015). Social pain and the brain: Controversies, questions, and where to go from here. Annual Review of Psychology, 66(1), 601-629.

Emmenegger, P., Marx, P., \& Schraff, D. (2017). Off to a bad start: Unemployment and political interest during early adulthood. Journal of Politics, 79(1), 315-328.

Frank, R. H. (2007). Falling behind: How income inequality harms the middle class. Oakland, CA: University of California Press.

Fredrickson, B. L. (2013). Positive emotions broaden and build. In P. Devine, \& A. Plant (Eds.), Advances in experimental social psychology (Vol. 47, pp. 1-53). Burlington, VT: Academic Press.

Gidron, N., \& Hall, P. A. (2017). The politics of social status: Economic and cultural roots of the populist right. British Journal of Sociology, 68(S1), S57-S84.

Golder, M. (2016). Far right parties in Europe. Annual Review of Political Science, 19(1), 477-497.

Hameleers, M., Bos, L., \& de Vreese, C. H. (2017). "They did it": The effects of emotionalized blame attribution in populist communication. Communication Research, 44(6), 870-900.

Hameleers, M., Bos, L., \& de Vreese, C. H. (2018). Selective exposure to populist communication: How attitudinal congruence drives the effects of populist attributions of blame. Journal of Communication, 68(1), 51-74.

Hegtvedt, K. A., \& Parris, C. L. (2014). Emotions in justice processes. In J. E. Stets \& J. H. Turner (Eds.), Handbook of the sociology of emotions (Vol. II, pp. 103-125). New York, NY: Springer.

Hochschild, A. R. (2016). Strangers in their own land: Anger and mourning on the American right. New York, NY: The New Press.

Jasper, J. M. (2018). The emotions of protest. Chicago, IL: University of Chicago Press.

Jost, J. T. (2019). Anger and authoritarianism mediate the effects of fear on support for the Far Right-What Vasilopoulos et al. (2019) really found. Political Psychology, 40(4), 705-711.

Keltner, D., \& Lerner, J. S. (2010). Emotion. In S. T. Fiske, D. T. Gilbert, \& L. Gardner (Eds.), Handbook of social psychology (Vol. 2, 5th ed., pp. 317-352). Hoboken, NJ: Wiley \& Sons.

Kemper, T. D. (2017). Elementary forms of social relations: Status, power and reference groups. Abingdon, UK: Routledge. 
Kiewiet, D. R., \& Lewis-Beck, M. S. (2011). No man is an island: Self-interest, the public interest, and sociotropic voting. Critical Review, 23(3), 303-319.

Lamont, M. (2019). From "having" to "being": Self-worth and the current crisis of American society. British Journal of Sociology, 70(3), 660-707.

Lamont, M., Park, B. Y., \& Ayala-Hurtado, E. (2017). Trump's electoral speeches and his appeal to the American white working class. British Journal of Sociology, 68(S1), S153-S180.

Lamprianou, I., \& Ellinas, A. A. (2019). Emotion, sophistication and political behavior: Evidence from a laboratory experiment. Political Psychology, 40(4), 859-876.

Lerner, J. S., Li, Y., Valdesolo, P., \& Kassam, K. S. (2015). Emotion and decision making. Annual Review of Psychology, 66(1), 799-823.

Lewis, M. (2016). Self-conscious emotions: Embarrassment, pride, shame, guilt, and hubris. In L. F. Barrett, M. Lewis, \& J. M. Haviland-Jones (Eds.), Handbook of emotions (4th ed., pp. 792-814). New York, NY: Guilford Press.

Magni, G. (2017). It's the emotions, Stupid! Anger about the economic crisis, low political efficacy, and support for populist parties. Electoral Studies, 50(1), 91-102.

Marcus, G. E., Neuman, W. R., \& MacKuen, M. B. (2017). Measuring emotional response: Comparing alternative approaches to measurement. Political Science Research Methods, 5(4), 733-754.

Margalit, Y. (2013). Explaining social policy preferences: Evidence from the great recession. American Political Science Review, 107(1), 80-103.

Margalit, Y. (2019). Political responses to economic shocks. Annual Review of Political Science, 22(1), 277-295.

Marx, P. (2016). The insider-outsider divide and economic voting: Testing a new theory with German electoral data. SocioEconomic Review, 14(1), 97-118.

Marx, P., \& Nguyen, C. (2018). Anti-elite parties and political inequality: How challenges to the political mainstream reduce income gaps in internal efficacy. European Journal of Political Research, 57(4), 919-940.

Mols, F., \& Jetten, J. (2017). The wealth paradox: Economic prosperity and the hardening of attitudes. Cambridge: Cambridge University Press.

Mudde, C., \& Rovira Kaltwasser, C. (2018). Studying populism in comparative perspective: Reflections on the contemporary and future research agenda. Comparative Political Studies, 51(13), 1667-1693.

Nguyen, C. (2019). Emotions and populist support. Retrieved from https://doi.org/10.31235/osf.io/e2wm6

Rico, G., Guinjoan, M., \& Anduiza, E. (2017). The emotional underpinnings of populism: How anger and fear affect populist attitudes. Swiss Political Science Review, 23(4), 444-461.

Ridgeway, C. L. (2014). Why status matters for inequality. American Sociological Review, 79(1), 1-16.

Rooduijn, M., \& Burgoon, B. (2018). The paradox of well-being: Do unfavorable socioeconomic and sociocultural contexts deepen or dampen radical left and right voting among the less well-off? Comparative Political Studies, 51(13), 1720-1753.

Rooduijn, M., van der Brug, W., \& de Lange, S. L. (2016). Expressing or fuelling discontent? The relationship between populist voting and political discontent. Electoral Studies, 43(1), 32-40.

Salmela, M., \& von Scheve, C. (2017). Emotional roots of right-wing political populism. Social Science Information, 56(4), 567-595.

Scheff, T. J., \& Retzinger, S. M. (1991). Emotions and violence: Shame and rage in destructive conflicts. New York, NY: Lexington.

Scherer, K. R., \& Moors, A. (2019). The emotion process: Event appraisal and component differentiation. Annual Review of Psychology, 70(1), 719-745.

Schumacher, G., \& van Kersbergen, K. (2016). Do mainstream parties adapt to the welfare chauvinism of populist parties? Party Politics, 22(3), 300-312.

Sennett, R. (2006). The culture of the new capitalism. New Haven, CT: Yale University Press.

Smith, H. J., Cronin, T., \& Kessler, T. (2008). Anger, fear, or sadness: Faculty members' emotional reactions to collective pay disadvantage. Political Psychology, 29(2), 221-246.

Sniderman, P. M. (2018). Some advances in the design of survey experiments. Annual Review of Political Science, 21(1), 259-275.

Sniderman, P. M., \& Brody, R. A. (1977). Coping: The ethic of self-reliance. American Journal of Political Science, 21(3), 501-521.

Spruyt, B., Keppens, G., \& Van Droogenbroeck, F. (2016). Who supports populism and what attracts people to it? Political Research Quarterly, 69(2), 335-346.

Stockemer, D., Lentz, T., \& Mayer, D. (2018). Individual predictors of the radical right-wing vote in Europe: A meta-analysis of articles in peer-reviewed journals (1995-2016). Government and Opposition, 53(3), 569-593.

Stuewig, J., Tangney, J. P., Heigel, C., Harty, L., \& McCloskey, L. (2010). Shaming, blaming, and maiming: Functional links among the moral emotions, externalization of blame, and aggression. Journal of Research in Personality, 44(1), 91-102. 
Suhay, E., \& Erisen, C. (2018). The role of anger in the biased assimilation of political information. Political Psychology, 39(4), 793-810.

Tangney, J. P., Stuewig, J., \& Mashek, D. J. (2007). Moral emotions and moral behavior. Annual Review of Psychology, 58, 345-372.

Turner, J. H. (2015). Revolt from the middle: Emotional stratification and change in post-industrial societies. London, UK: Routledge.

Valentino, N. A., Brader, T., Groenendyk, E. W., Gregorowicz, K., \& Hutchings, V. L. (2011). Election night's alright for fighting: The role of emotions in political participation. Journal of Politics, 73(1), 156-170.

Vasilopoulos, P., Marcus, G. E., Valentino, N. A., \& Foucault, M. (2019). Fear, anger, and voting for the far right: Evidence from the November 13, 2015 Paris terror attacks. Political Psychology, 40(4), 679-704.

Wagner, M. (2014). Fear and anger in Great Britain: Blame assignment and emotional reactions to the financial crisis. Political Behavior, 36(3), 683-703.

Walker, R. (2014). The shame of poverty. Oxford: Oxford University Press.

Webster, S. W. (2018). Anger and declining trust in government in the American electorate. Political Behavior, 40(4), 933-964.

Weiner, B. (2006). Social motivation, justice, and the moral emotions: An attributional approach. New York, NY: Psychology Press.

Winkelmann, R. (2012). Conspicuous consumption and satisfaction. Journal of Economic Psychology, 33(1), $183-191$.

Wirz, D. (2018). Persuasion through emotion? An experimental test of the emotion-eliciting nature of populist communication. International Journal of Communication, 12(1), 1114-1138.

Wirz, D. S., Wettstein, M., Schulz, A., Müller, P., Schemer, C., Ernst, N., ... Wirth, W. (2018). The effects of right-wing populist communication on emotions and cognitions toward immigrants. International Journal of Press/Politics, 23(4), 496-516.

\section{SUPPORTING INFORMATION}

Additional supporting information may be found online in the Supporting Information section.

How to cite this article: Marx P. Anti-elite politics and emotional reactions to socio-economic problems: Experimental evidence on "pocketbook anger" from France, Germany, and the United States. Br J Sociol. 2020;71:608-624. https://doi.org/10.1111/1468-4446.12750 


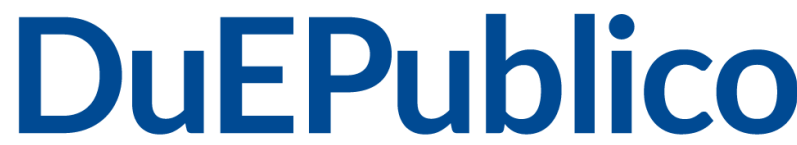

Duisburg-Essen Publications online
UNIVERSITÄT

DEUSISEN R G

Offen im Denken

$\mathbf{U b} \mid \begin{aligned} & \text { universitäts } \\ & \text { bibliothek }\end{aligned}$

This text is made available via DuEPublico, the institutional repository of the University of Duisburg-Essen. This version may eventually differ from another version distributed by a commercial publisher.

DOI: $\quad 10.1111 / 1468-4446.12750$

URN: urn:nbn:de:hbz:464-20210415-092140-0 